\title{
A systematic review of the prevalence and predictors of the double burden of malnutrition within households
}

\author{
Satoko Kosaka* and Masahiro Umezaki \\ Department of Human Ecology, School of International Health, Graduate School of Medicine, The University of Tokyo, \\ 7-3-1 Hongo, Bunkyo-ku, Tokyo 113-0033, Japan
}

(Submitted 15 September 2016 - Final revision received 6 March 2017 - Accepted 15 March 2017-First published online 18 May 2017)

\section{Abstract}

Recently, increasing attention has been paid to the emergence of the double burden of malnutrition within households. We provide an overview of the literature regarding this phenomenon by reviewing previous studies of the prevalence of double-burden households and associated factors together with the research methods used. Studies were identified from the electronic databases PubMed and Web of Science, using the same search terms for both. A total of thirty-five articles met the eligibility criteria, and 367 sets of prevalence data were extracted. In all, thirty-four articles were published in 2000 or later; twenty-four used secondary data and twenty-five focused on mother-child pairs. The ages of children varied from 0 to 19 years. All the studies used BMI as a nutritional indicator for adults. For children, height-for-age was most frequently used, whereas weight-for-age, weight-for-height and BMI-for-age were also used in multiple studies. The reported national prevalence of doubleburden households varied from $0 \cdot 0$ to $26 \cdot 8 \%$ by country and year; however, few studies were directly comparable, because of differences in the combinations of undernourished and overweight persons, age ranges, nutritional indicators and cut-off points. Whereas many focused on African countries, a few involved Asian countries. Although urban residence, income and education were frequently assessed, the role of intermediate factors in nutritional status, such as diet and physical activity, remains unclear. It is recommended that future studies use comparable indicators and cut-off points, involve Asian countries, and investigate individual diet and physical activity.

\section{Key words: Double burden: Malnutrition: Households: Undernutrition: Overweight}

The recent increase in overweight/obesity is sometimes said to be a pandemic and is recognised not only by researchers and policy makers but also by the public. Obesity is one of the most important causes of non-communicable diseases (NCD) in developed countries and is itself an $\mathrm{NCD}^{(1)}$. Recently, a high prevalence of obesity has also been reported in some developing countries in which a large percentage of deaths is attributable to $\mathrm{NCD}^{(2)}$. Health policies in developing countries, which have until now been focused on undernutrition, must now also address the increasing prevalence of overweight. Because both now coexist, policies must focus on overweight simultaneously with undernutrition.

Generally, the decrease in undernutrition and increase in overweight/obesity are described together with the nutrition transition $^{(3)}$. The nutrition transition refers to a series of changes in dietary patterns that have occurred throughout human history, driven by social and economic factors that have varied from the onset of animal husbandry and agriculture in the early ages to industrialisation and urbanisation over the last few centuries $^{(4)}$. On this spectrum, the changes in body composition we are facing now are a consequence of the shift away from a diet primarily based on staple grains, vegetables and fruits that are locally available, towards a diet higher in fat, sugar, animalorigin foods and processed food that is lower in fibre ${ }^{(5)}$. Today, more generally, the idea of the nutrition transition is also considered to include a series of changes in physical activity in addition to dietary changes, and both factors contribute to changes in body composition.

In contrast to Western countries, which have experienced this transition over a long period, developing countries are experiencing it at a much faster rate $e^{(6,7)}$. As a consequence of the rapidity and drastic nature of these changes, the highest rate of growth in the prevalence of overweight/obesity from 1980 to 2008 was in Southeast Asia, followed by Oceania, Sub-Saharan Africa and Latin America ${ }^{(7)}$.

The decrease in undernutrition is not proportional to the increase in overweight/obesity. Using data from multiple countries and years, Ruel et al. ${ }^{(8)}$ estimated that, with a $10 \%$ increase in gross domestic product per person, the rate of stunting in children and underweight in women decreased by 5.9 and $4.0 \%$, respectively, whereas the rate of overweight/obesity in women increased by $7 \cdot 0 \%$. Because of the gap between these rates, many developing countries are now simultaneously facing an increasingly high prevalence of overweight together with

Abbreviations: HAZ, height-for-age $z$-score; NCHS, US National Center for Health Statistics.

* Corresponding author: S. Kosaka, fax +81 35841 3395, email satoco@humeco.m.u-tokyo.ac.jp 
persistent undernutrition. This coexistence of undernutrition and overnutrition is termed the 'double burden of malnutrition'. This is defined in several ways, as it can occur at several levels; that is, the population level (e.g. high prevalence of overweight and undernutrition in the same population), the household level or mother-child pairs (e.g. an overweight mother with a stunted child) and the individual level (e.g. overweight with micronutrient deficiency within an individual).

In the last decade, increasing attention has been paid to the emergence of the double burden of malnutrition within households, that is, the coexistence of overweight and undernutrition among the members of a single household. However, no review articles primarily on this topic have been published in scientific journals. The phenomenon of the double burden within households has been mentioned in review articles whose main topics were, for example, obesity in developing countries $^{(9)}$ and maternal health ${ }^{(10)}$. A discussion paper by the World Bank attempted to review the causes of and possible solutions for the double burden at the individual, household and country levels ${ }^{(6)}$. However, most of the discussion was devoted to the double burden at the country level, and the double burden within households was little discussed. A comprehensive assessment of the prevalence and predictors of the double burden within households across countries is thus lacking.

This study is a systematic review of the current literature on the double burden of malnutrition within households.

\section{Methods}

\section{Inclusion criteria}

The criteria below were used to identify eligible studies:

- original analyses either using secondary data or based on an original survey; thus, review articles were excluded (no meta-analyses were found);
- studies that reported the prevalence of households with a double burden of malnutrition;

- studies published up to the end of June 2015; and

- studies with the full text available in English.

\section{Information sources, search and study selection}

Studies were identified using the electronic databases PubMed and Web of Science. The following search terms were used: '(dual OR double) burden (malnutrition OR household)'. After screening the records in the search results by titles and abstracts, the authors examined the full-text versions of all identified articles to determine their potential eligibility. During this eligibility assessment, the literature cited was also screened on the basis of the titles, and the studies judged eligible were added to the pool of potential articles that would be examined. This process is illustrated in a flow diagram together with the number of records in Fig. 1.

A post hoc search was conducted to confirm that the single search term was sufficient and resulted in the same list of articles (see the online Supplementary Material S1 for the search terms).

\section{Data collection}

Information was extracted from eligible studies using a data extraction form. Below are the items included in the database (or data extraction form):

- publication information: name of journal, year of publication, volume and page numbers.

- data: country, area, data source, year of data collection, characteristics of subjects (e.g. slum residents, refugees) and number of subjects analysed;

- methods: focused combination of undernourished and overnourished persons (e.g. overweight mother and

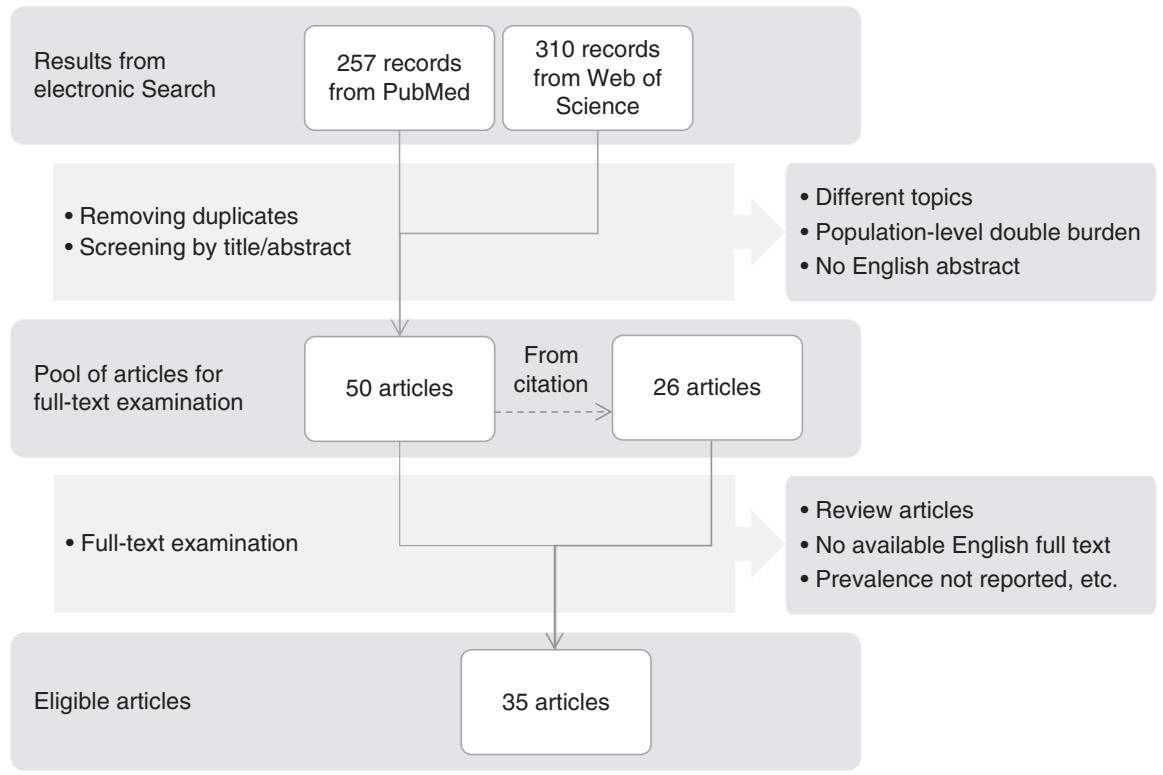

Fig. 1. Selection process and the number of articles included in the review. 
undernourished child), age range of adults and children, and nutritional indicators used to identify undernutrition and overnutrition of adults and children; and

- results: the number and prevalence of households/pairs with a double burden of malnutrition, together with associated factors.

For the sake of comparison, crude prevalence rates were preferentially retrieved if available, as some studies reported only crude (unadjusted) values. For this purpose, the number of cases was retrieved in addition to the reported prevalence. For studies that analysed multiple data sets (multiple countries and/or years) or that used multiple indicators, information for each result was extracted. For associated factors examined by comparison with other household/pair categories, information on the compared category was also retrieved.

\section{Results}

\section{Study selection and data collection}

Finally, thirty-five articles were identified as eligible for inclusion in the current review. Fig. 1 shows a flow diagram of the selection process and the number of records in each phase. After removing duplicates and screening by the titles and abstracts, fifty articles remained for the full-text examination. Reasons for exclusion during the full-text examination included the following: narrative reviews with no analysis of original data (nine articles), no English-language full text available (five), the prevalence of double-burden households/pairs not reported (three), different focus (two; e.g. on the association between maternal height and child body fat), or the double burden of malnutrition examined at the population level (three).

Examination of the reference lists of the fifty articles resulted in identification of a further twenty-six potentially eligible articles. Of these, nineteen were excluded because of the following reasons: being narrative review articles (six articles), having a different focus (four), prevalence not being reported (three), the focus on the double burden of malnutrition being at the individual level (two) or at the population level (one), being one of multiple publications (two), or no English full-text version being available (one).

Using the data extraction form, 367 prevalence values were obtained from thirty-five articles.

\section{Study characteristics}

The characteristics of the included studies are shown in the online Supplementary Material S2 and summarised in Table 1. With the exception of one study published in 1995, all studies were published in 2000 or later, with twenty-three being published in 2010 or later.

Of the thirty-five articles, twenty-four used secondary data such as Demographic and Health Surveys (six articles). In total, seventy countries were identified in the extracted data, of which sixtyseven were low- or middle-income countries, and thirty-seven were in Africa, sixteen in Asia, thirteen in the Americas, two in Europe and two in the Caribbean. Some of them limited the focus on specific settings or populations within the country, such as slums ${ }^{(11)}$, indigenous people ${ }^{(21)}$, and refugees in an emergency situation $^{(25)}$. Of the 367 sets of data extracted, the year of data collection ranged from 1988 to 2012. Only five studies reported prevalence rates in multiple years for each country.

Overall, the analytical methods varied markedly across studies. Among the thirty-five studies, twenty-five limited their focus to pairs of undernourished children and overweight mothers. The age range of the children and adults varied among studies; one study categorised 19-year-old individuals as children, whereas another study categorised 12-year-olds as adults. BMI was a commonly used indicator for the nutritional status of adults: as the cut-off point for overweight in adults, thirty-one studies used a BMI value of $25.0 \mathrm{~kg} / \mathrm{m}^{2}$, three used $30.0 \mathrm{~kg} / \mathrm{m}^{2}$, and two used $23.0 \mathrm{~kg} / \mathrm{m}^{2}$ (for Indonesia ${ }^{(14,31)}$ and Bangladesh ${ }^{(27)}$ ). Indicators of a child's nutritional status differed somewhat among the studies. Although the height-for-age $z$-score (HAZ) was most frequently used, weight-for-age $z$-score (WAZ), weight-for-height $z$-score (WHZ) and BMI-forage $z$-score were also used in multiple studies. In all, thirteen studies involved children in the same age range, a combination of undernourished and overweight persons, and nutrition indicators and cut-off points; these calculated the prevalence of pairs of children $<2$ years old with an HAZ score of $<-2$ and mothers with a BMI value higher than $25 \cdot 0 \mathrm{~kg} / \mathrm{m}^{2}$. Among studies that used $z$-scores, the WHO references released in 2006 for children $<5$ years old and in 2007 for those aged 5-19 years were used most frequently for classification.

The numbers of samples and the sampling methods also varied markedly among the studies. The maximum difference in sample size was $>250$-fold (forty-one ${ }^{(30)}$ and $10317^{(38)}$ ). Among eleven studies that analysed primary data, four did not describe their sampling methods.

Of the thirty-five studies, eighteen reported prevalence value(s) but without specifying the actual numbers of households/pairs identified as experiencing a double burden of malnutrition. In all, twenty-five studies reported factors associated with the double burden within households together with the prevalence. A wide variety of factors were assessed, from community social capital to intestinal parasites. Frequently assessed factors included maternal age and education, urban/rural residence, household size and income. Three studies explored physical activity levels, and another three studies explored individual dietary factors.

The reference group used for comparison with doubleburden households/pairs to explore associated factors differed among the studies and some conducted multiple comparisons using different reference groups. Four categories were used as references: normal only (households/pairs with no undernourished or overweight person), undernourished (those with undernourished person(s) but no overweight person), overweight (those with overweight person(s) but no undernourished person) and all other than double-burden households/pairs. The most commonly used reference group was normal only (eleven studies), followed by nine studies in which double-burden households/pairs were compared with all other households/pairs (i.e. normal only, undernourished and overweight households/pairs). 


\section{Nesitish Journal of Nutrition}

Table 1. Characteristics of included studies (in chronological order of publication)

\begin{tabular}{|c|c|c|c|c|c|c|c|c|c|c|c|c|}
\hline \multirow{2}{*}{$\begin{array}{l}\text { Year of } \\
\text { publication }\end{array}$} & \multirow[b]{2}{*}{ Country } & \multirow[b]{2}{*}{ Data } & \multirow[b]{2}{*}{ Analysis } & \multirow[b]{2}{*}{$\begin{array}{l}\text { Year of data } \\
\text { source }\end{array}$} & \multirow[b]{2}{*}{$\begin{array}{l}\text { No. of sampled } \\
\mathrm{HHs} / \text { pairs }\end{array}$} & \multirow[b]{2}{*}{ Combination of UN and ON } & \multicolumn{2}{|c|}{ Adult } & \multicolumn{2}{|c|}{ Child } & \multirow[b]{2}{*}{ Notes } & \multirow[b]{2}{*}{$\begin{array}{l}\text { Reference } \\
\text { no. }\end{array}$} \\
\hline & & & & & & & $\begin{array}{l}\text { Age range } \\
\text { (years) }\end{array}$ & Indicator & Age range & Indicator & & \\
\hline 1995 & Brazil & $P$ & CS & 1990-1991 & 535 & UN child and ON adult & $\geq 18$ & BMI & $\leq 10$ years & WAZ & $\begin{array}{l}\text { Sao Paulo (slum), Sampling method } \\
\text { unknown }\end{array}$ & 11 \\
\hline 2000 & $\begin{array}{l}\text { Brazil, China } \\
\text { and Russia }\end{array}$ & $\mathrm{s}$ & CS & 1989-1996 & Varied & at least $1 \mathrm{ON}$ person and $1 \mathrm{UN}$ person & $\geq 18$ & BMI & $2-18$ years & BMI & National representative surveys & 12 \\
\hline 2002 & China & $\mathrm{s}$ & CS & 1993 & 3340 & $\begin{array}{l}\text { at least } 1 \mathrm{UN} \text { person and at least } 1 \mathrm{ON} \\
\text { person }\end{array}$ & $\geq 18$ & BMI & $6-18$ years & BMI & Representative of 8 provinces & 13 \\
\hline 2003 & Philippines & $\mathrm{P}$ & CS & N/A & 376 & UN child and ON mother & $\geq 18$ & BMI & 33-83 months & WAZ & $\begin{array}{l}\text { Manila (urban, poor), Purposive } \\
\text { sampling }\end{array}$ & 14 \\
\hline 2003 & Malaysia & $\mathrm{P}$ & CS & N/A & 140 & UN child and ON mother & $\geq 20$ & BMI & $1-6$ years & WAZ & $\begin{array}{l}\text { Sabak Bernam (rural, poor), Inventory } \\
\text { survey }\end{array}$ & 15 \\
\hline 2005 & 7 countries & $\mathrm{s}$ & CS & 1988-1996 & Varied & at least $1 \mathrm{UN}$ person and $1 \mathrm{ON}$ person & $\geq 18$ & BMI & $2-18$ years & $\mathrm{BMI}$ & National representative surveys & 3 \\
\hline 2005 & 36 countries & $\mathrm{s}$ & CS & 1991-1998 & Varied & UN child and ON mother & $\geq 18$ & BMI & $6-60$ months & HAZ & National representative surveys (DHS) & 16 \\
\hline 2005 & 42 countries & $\mathrm{s}$ & CS & 1992-2001 & $N / A$ & UN child and ON mother & $\geq 18$ & BMI & $6-60$ months & HAZ & National representative surveys (DHS) & 17 \\
\hline 2005 & Haiti & $P$ & CS & 2003 & 203 & UN child and ON mother & $\mathrm{N} / \mathrm{A}$ & BMI & $6-59$ months & WHZ, HAZ & $\begin{array}{l}\text { Petion-Ville (urban slum), Random } \\
\text { sampling }\end{array}$ & 18 \\
\hline 2007 & Mexico & $\mathrm{s}$ & CS & 1998-1999 & 5983 & UN child and ON mother & $12-49$ & $\begin{array}{l}\text { BMI, WC, } \\
\text { WHR }\end{array}$ & $\leq 5$ years & HAZ & National representative survey & 19 \\
\hline 2009 & 18 countries & $\mathrm{s}$ & CS & 1998-2004 & Varied & UN child and ON mother & $13-49$ & $\mathrm{BMI}$ & $3-5$ years & WAZ & National representative surveys (DHS) & 20 \\
\hline 2009 & Malaysia & $\mathrm{P}$ & CS & 2002-2005 & 182 & UN child and ON mother & $18-55$ & BMI & $\leq 9$ years & WAZ & $\begin{array}{l}\text { Indigenous people in Selangor, } \\
\text { Inventory survey }\end{array}$ & 21 \\
\hline 2012 & Cape Verde & $\mathrm{s}$ & CS & 2001-2002 & 1571 & At least $1 \mathrm{UN}$ person and $1 \mathrm{ON}$ person & 18 & BMI & $\leq 18$ years & WHZ, BAZ & National representative survey & 24 \\
\hline 2012 & Algeria & $\mathrm{P}$ & CS & 2010 & 1066 & $\begin{array}{l}\text { At least } 1 \text { child or woman of } U N \text { and at } \\
\text { least } 1 \text { child or woman of ON }\end{array}$ & $15-49$ & HAZ, BMI & $\leq 5$ years & $\begin{array}{l}\text { WHZ, HAZ, WAZ, } \\
\text { BAZ, oedema }\end{array}$ & $\begin{array}{l}\text { Refugees in protracted emergency } \\
\text { setting, Probability/random sampling }\end{array}$ & 25 \\
\hline 2012 & Guatemala & $\mathrm{s}$ & CS & 2000 & 2492 & UN child and ON mother & $18-49$ & BMI & $6-60$ months & HAZ & National representative survey & 26 \\
\hline 2012 & $\begin{array}{l}\text { Bangladesh } \\
\text { and } \\
\text { Indonesia }\end{array}$ & $\mathrm{s}$ & CS & $2000-2006$ & varied & UN child and ON mother & N/A & BMI & $6-59$ months & HAZ & $\begin{array}{l}\text { Rural data of national representative } \\
\text { surveys }\end{array}$ & 27 \\
\hline 2012 & Mexico & $P$ & CS & 2010 & 58 & UN child and ON mother & $\begin{array}{c}\text { N/A ( } 34.3 \text { years } \\
\text { on average) }\end{array}$ & BMI & $\begin{array}{l}\text { N/A ( } 8.4 \text { years } \\
\text { on average) }\end{array}$ & HAZ & $\begin{array}{l}\text { Maya (urban), Sampling method } \\
\text { unknown }\end{array}$ & 28 \\
\hline 2013 & Malaysia & $P$ & CS & $\mathrm{N} / \mathrm{A}$ & 223 & UN child and ON mother & $18-55$ & BMI & $2-12$ years & WAZ & $\begin{array}{l}\text { Bachok (rural, poor), Purposive } \\
\text { sampling }\end{array}$ & 29 \\
\hline 2013 & Venezuela & $P$ & CS & 2010 & 41 & $\begin{array}{l}\text { At least } 1 \mathrm{UN} \text { child and at least } 1 \mathrm{ON} \\
\text { adult }\end{array}$ & $\geq 19$ & BMI & $0-19$ years & HAZ & $\begin{array}{l}\text { Carabobo (rural), Sampling method } \\
\text { unknown }\end{array}$ & 30 \\
\hline 2013 & Indonesia & $\mathrm{s}$ & L & 1993-2007 & Varied & At least $1 \mathrm{UN}$ person and $1 \mathrm{ON}$ person & $\geq 19$ & BMI & $2-19$ years & BAZ & National representative survey & 31 \\
\hline 2014 & Argentina & $\mathrm{P}$ & CS & 2005 & 136 & At least $1 \mathrm{UN}$ child and $\mathrm{ON}$ mother & $\bar{N} / \mathrm{A}$ & $\mathrm{BMI}$ & $2-18$ years & HAZ & Andean, Sampling method unknown & 32 \\
\hline 2014 & Brazil & $\mathrm{s}$ & CS & $\begin{array}{c}1974-2009 \\
(2006-2007)\end{array}$ & 4390 & UN child and ON mother & $\mathrm{N} / \mathrm{A}$ & BAZ, BMI & $\leq 5$ years & HAZ & National representative surveys (DHS) & 33 \\
\hline 2014 & Ecuador & $\mathrm{s}$ & CS & 2012 & 8078 & UN child and ON mother & $\leq 59$ & BAZ, BMI & $\leq 5$ years & HAZ & National representative survey & 34 \\
\hline 2014 & Mexico & $\mathrm{s}$ & CS & 2012 & 4777 & UN child and ON mother & $\leq 49$ & $\mathrm{BAZ}, \mathrm{BMI}$ & $\leq 5$ years & $\mathrm{HAZ}$ & National representative survey & 35 \\
\hline 2014 & Mexico & $\mathrm{P}$ & CS & 2003-2004 & 1547 & UN child and ON mother & $18-49$ & BMI & $0-5$ years & HAZ & $\begin{array}{l}\text { Rural poor communities, Random } \\
\text { sampling }\end{array}$ & 36 \\
\hline 2014 & Guatemala & $\mathrm{s}$ & CS & 2008 & 9320 & UN child and ON mother & $15-49$ & BMI & $0-59$ months & HAZ & National representative survey & 37 \\
\hline 2014 & Colombia & $\mathrm{s}$ & CS & 2010 & 10317 & UN child and ON mother & $18-49$ & BAZ, BMI & $\leq 5$ years & HAZ & National representative survey & 38 \\
\hline 2014 & Uruguay & $\mathrm{s}$ & CS & 2004-2011 & 1532 & UN child and ON mother & N/A & BMI & 6 years & HAZ & National representative survey & 39 \\
\hline 2015 & Kenya & $\mathrm{s}$ & CS & 2010 & 6308 & UN child and ON mother & $\geq 18$ & BMI & $\leq 5$ years & HAZ, WAZ, WHZ & Nairobi (urban slums), Inventory survey & 43 \\
\hline 2015 & Colombia & $\mathrm{s}$ & $\mathrm{L}$ & $2000-2010$ & Varied & $\begin{array}{l}\text { At least } 1 \text { UN child and ON mother, or at } \\
\text { least } 1 \text { ON child and UN mother }\end{array}$ & $\bar{N} / \mathrm{A}$ & BMI & $\leq 5$ years & HAZ, BAZ & National representative survey & 44 \\
\hline
\end{tabular}

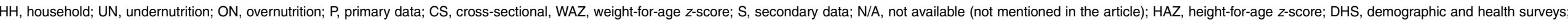
WHZ, weight-for-height $z$-score; WC, waist circumference; WHR, waisthip ratio; L, longitudinal; BAZ, BMI Z-score.

Only for countries with data of multiple years. If the author(s) did not mention, the columns are filled with ' $N / A$ '. 
Table 2. Latest national prevalence of the stunted child and overweight/ obese mother pairs by country*

\begin{tabular}{|c|c|c|c|}
\hline Countries & Year of data & Prevalence (\%) & Reference no. \\
\hline Armenia & 2005 & 3.2 & 23 \\
\hline Azerbaijan & 2006 & 8.5 & 23 \\
\hline Bangladesh & 2000 & 1.0 & 17 \\
\hline Benin & 2006 & 3.5 & 23 \\
\hline Bolivia & 2008 & 7.9 & 23 \\
\hline Brazil & $2006-2007$ & 2.6 & 33 \\
\hline Burkina Faso & 2003 & 1.5 & 23 \\
\hline Cambodia & 2005 & 2.9 & 23 \\
\hline Cameroon & 2004 & $5 \cdot 3$ & 23 \\
\hline Central African Republic & 1994 & $1 \cdot 4-2 \cdot 5$ & $16,17,23$ \\
\hline Chad & 2003 & 3.0 & 23 \\
\hline Colombia & 2005 & 3.6 & 23 \\
\hline Comoros & 1996 & $3.5-5 \cdot 6$ & $16,17,23$ \\
\hline Congo & 2005 & 4.4 & 23 \\
\hline Cote d'Ivoire & 1998 & $2 \cdot 5-3 \cdot 1$ & 17,23 \\
\hline Dominican Republic & 1996 & 2.2 & 17,23 \\
\hline DR Congo & 2007 & 2.9 & 23 \\
\hline Ecuador & 2012 & $13 \cdot 1$ & 34 \\
\hline Egypt & 2008 & $16 \cdot 0$ & 23 \\
\hline Ethiopia & 2005 & $1 \cdot 1$ & 23 \\
\hline Gabon & 2000 & 3.3 & 23 \\
\hline Ghana & 2008 & 2.7 & 23 \\
\hline Guatemala & 2008 & $20 \cdot 0$ & 37 \\
\hline Guinea & 2005 & 2.2 & 23 \\
\hline Haiti & 2005 & $2 \cdot 0$ & 23 \\
\hline Honduras & 2005 & 7.9 & 23 \\
\hline India & 2005 & 2.3 & 23 \\
\hline Jordan & 2009 & 4.3 & 23 \\
\hline Kazakhstan & 1999 & 1.4 & 23 \\
\hline Kenya & 2008 & 4.7 & 23 \\
\hline Kyrgyz Republic & 1997 & $3.9-4.5$ & $16,17,23$ \\
\hline Lesotho & 2004 & 11.7 & 23 \\
\hline Madagascar & 2008 & 1.7 & 23 \\
\hline Malawi & 2004 & 3.8 & 23 \\
\hline Mali & 2006 & 4.5 & 23 \\
\hline Mexico & 2012 & 8.4 & 35 \\
\hline Moldova & 2005 & 2.7 & 23 \\
\hline Morocco & 2003 & $5 \cdot 4$ & 23 \\
\hline Mozambique & 2003 & $2 \cdot 8$ & 23 \\
\hline Namibia & 2006 & 4.5 & 23 \\
\hline Nepal & 2006 & 0.9 & 23 \\
\hline Nicaragua & 2001 & $5 \cdot 9-6 \cdot 9$ & 17,23 \\
\hline Niger & 2006 & 4.3 & 23 \\
\hline Nigeria & 2008 & $5 \cdot 2$ & 23 \\
\hline Peru & 2004 & 8.5 & 23 \\
\hline Rwanda & 2005 & 3.2 & 23 \\
\hline Senegal & 2005 & 2.0 & 23 \\
\hline Sierra Leone & 2008 & $7 \cdot 1$ & 23 \\
\hline Swaziland & 2006 & $10 \cdot 3$ & 23 \\
\hline Tanzania & 2004 & 3.3 & 23 \\
\hline Togo & 1998 & $1.5-2 \cdot 0$ & $16,17,23$ \\
\hline Turkey & 1998 & 6.9 & 23 \\
\hline Uganda & 2006 & 1.9 & 23 \\
\hline Uruguay & 2004-2006 & 6.3 & 39 \\
\hline Uzbekistan & 1996 & $3.9-5.5$ & $16,17,23$ \\
\hline Zambia & 2007 & 4.8 & 23 \\
\hline Zimbabwe & 2005 & $5 \cdot 0$ & 23 \\
\hline
\end{tabular}

* Obesity: having a BMI $\geq 30.0 \mathrm{~kg} / \mathrm{m}^{2}$. Overweight: having a BMl between 25.0 and $30.0 \mathrm{~kg} / \mathrm{m}^{2}$. Stunting: $<-2 \mathrm{SD}$ from mean height-for-age of the reference population.

\section{Prevalence of households with a double burden of malnutrition}

Table 2 summarises the latest national prevalence in terms of stunted child and overweight/obese mother pairs by country; all of the 367 prevalence values are shown in the online Supplementary Material S3.

The reported prevalence figures varied from 0.0 to $26 \cdot 8 \%$, varying by the combination of malnourished persons and nutritional indicators and by country. Of the 367 prevalence values extracted, 207 were national prevalence rates for stunted child and overweight mother pairs. Low-income countries tended to have a lower prevalence of this combination than middle-income countries. By geographical area, a low prevalence was more frequent in Asian countries than in African countries. Among the seven Asian countries examined, five had a prevalence of $<3 \%$ (Bangladesh, Cambodia, India, Kazakhstan and Nepal), compared with eight of thirty-four African countries (the Central African Republic, Burkina Faso, DR Congo, Ethiopia, Guinea, Madagascar, Mozambique, Senegal and Togo). The prevalence was $<10 \%$ in many countries; exceptions included Bolivia (7.3-11.5\%), Egypt (8.8-16.0\%) and Guatemala (10.7-20.7\%). Among forty-one countries that were analysed for multiple years using the same indicators/ cut-off points for the same combination of undernourished and overweight persons, the prevalence increased in twenty countries (eleven in Africa, five in Asia and four in Central and South America), decreased in nine countries (six in Africa, two in Asia and one in Central America) and did not change in one country between the earliest and most recent values (it differed depending on indicator and combination in eleven countries). In terms of national income, the prevalence increased more frequently in low-income countries (twelve of the twenty-five countries examined) than in middle-income countries (eight of the twenty-two countries examined).

The reported prevalence differed substantially by the age range set for children and adults; for example, Garrett \& Ruel $^{(16,17)}$ and Dieffenbach \& Stein ${ }^{(23)}$. They used the same indicators and cut-off points for both children and adults (a -2 HAZ for children and a BMI of $25.0 \mathrm{~kg} / \mathrm{m}^{2}$ for adults); however, Dieffenbach \& Stein ${ }^{(23)}$ limited the age range for children to 2-5 years old, whereas Garrett \& Ruel ${ }^{(16,17)}$ used a range of 6-60 months old in both of their studies. Garrett \& Ruel $^{(16,17)}$ generally estimated a higher prevalence than did Dieffenbach \& Stein. In addition, nineteen studies limited the age range in addition to the available age range of the secondary or reference data used. For example, Lee et al. ${ }^{(22)}$ used national representative data that surveyed all children in the households but excluded those $<12$ months and $>60$ months old. However, a justification for the limitation was provided in only three studies. Reasons given included the instability of HAZ for children $\leq 2$ years old ${ }^{(23)}$ and comparability issues with other studies ${ }^{(26)}$.

\section{Factors associated with the double burden of malnutrition within households}

Urban/rural residence, income and maternal/household-head education level were frequently assessed in terms of their association with the double burden within households. The results for these three factors are summarised in Table 3 by reference group. Whereas most studies have reported a positive relationship between urban residence and the double burden within households, results for household income and education were mixed.

(i) Urban/rural. A total of forty-one analytical cases explored the association between urban/rural residence and the double burden of households/pairs. In twenty-two cases there was a 
Table 3. Association between the double burden within households and frequently assessed factors: urban residence, income and household (HH)-heads' education

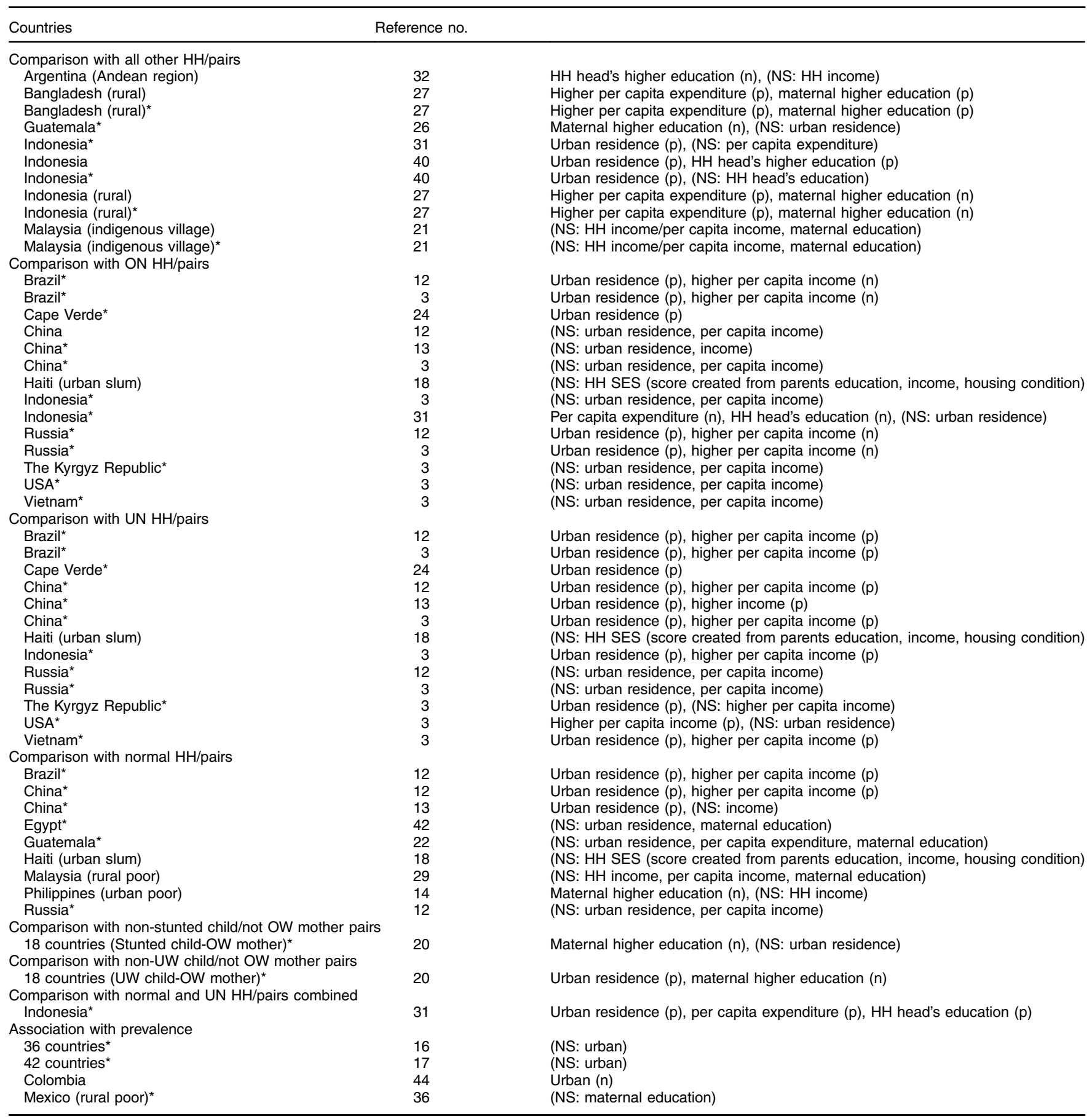

n, Negative association; p, positive association; ON, overnutrition; UN, undernutrition; SES, socioeconomic status; OW, overweight; UW, underweight.

* Controlled for confounding factors.

positive relationship with urban residence, in eighteen there was no significant relationship, and in one case there was a negative relationship.

Several possible links between urban residence and the double burden within households were proposed. Roemling \& Qaim $^{(31)}$ found that the prevalence of overweight households, as well as that of double-burden households, was higher in urban areas and noted that urban environments offer a greater variety of food choices, including processed or fast-food items and jobs with lower levels of physical activity. Doak et al. ${ }^{(13)}$ attributed the high probability of double-burden households being in urban areas to the fact that the nutrition transition begins in urban areas. In another article, Doak et al. ${ }^{(3)}$ explored the interaction between urban residence and income, and 
reported that, among the seven countries they assessed, the urban effect was somewhat less marked in low-income households in the Kyrgyz Republic, Russia and Vietnam, whereas the effect was greater in low-income households in China and Indonesia. However, the study did not investigate this further, or attempt to explain the mechanisms underlying these differences.

(ii) Income. Results regarding the relationship between income and the double burden were mixed. Compared with undernourished households, double-burden households tended to have a higher income, whereas many studies have found no significant difference in income when double-burden households were compared with normal households. In some studies, however, the sample size might have been too small to detect a significant relationship ${ }^{(21,32)}$.

As noted above, an interaction between income and urban residence has been reported ${ }^{(3)}$. Jehn \& Brewis ${ }^{(20)}$ suggested that this might be the cause of the mixed results, introducing a study that reported that, among Brazilian women who moved to urban areas and had insufficient income, the prevalence of both under- and overweight was higher than that among women who moved to urban areas and had a sufficient income.

(iii) Maternal/household-head education level. The association between nutritional status and educational background is also a focus of interest. Among thirteen studies that investigated this issue, four reported a negative relationship between higher education and the double burden within households, six found no significant relationship and one study reported a positive association, whereas two studies reported different relationships by reference group.

Those studies provided further insight into the link between education and the double burden. Jehn \& Brewis ${ }^{(20)}$ reported a decline in obesity rates with an increasing education level, and indicated that the double burden within households was a byproduct of the rapid increase in the prevalence of overweight in the absence of any substantial improvement in undernutrition. Also, an association between maternal education and child undernutrition has also been reported. Lee et al. ${ }^{(26)}$ showed that households with highly educated mothers were less likely to have a stunted child and less likely to be double-burden households. Vaezghasemi et $a l^{(40)}$, whereas, citing a paper by $\mathrm{Ra}^{(45)}$, noted that increasing education levels of mothers contribute to a better intake of protein and vitamins, which can improve nutritional status. Leroy et al. ${ }^{(36)}$ emphasised the effects of maternal education on mitigating the negative effects of wealth on child and maternal nutrition, possibly explaining the association between education and the double burden.

(iv) Other factors. In all, six studies reported the relationship between household-head sex and the double burden within households. Male-headed households were more likely to have a double burden in three analyses ${ }^{(31,34,40)}$ and less likely in one analysis $^{(29)}$. By contrast, children's sex was reported to have no significant association in all three studies in which it was examined $^{(21,27,36)}$
The mothers' or household heads' age was examined in eight studies. Compared with normal households and to all households without a double burden ${ }^{(23,27)}$, the households/pairs with a double burden were likely to have an older head or mother ${ }^{(31,42)}$. Compared with the overweight households, the household heads/mothers in the households/pairs with a double burden were also more likely to be younger ${ }^{(31)}$.

Doak et $a l^{(13)}$ used a secondary data set with household dietary information obtained by the 24-h recall method and compared the proportion of energy intake from carbohydrate, protein and fat in households with a double burden with that of households in other categories. Households with a double burden tended to have a lower percentage of energy intake from carbohydrates compared with underweight households and normal households, a higher percentage of energy intake from protein compared with normal households, and a higher percentage of energy intake from fat compared with underweight households. Interestingly, no significant differences were found when the double-burden households were compared with the overweight households.

\section{Discussion}

The obesity epidemic began to emerge in developing countries about two decades ago. Although undernutrition has long been a concern in developing countries, these countries are now experiencing an increasing prevalence of overweight. This study was a systematic review of the published literature, focusing on the double burden of malnutrition within households.

During the 20 years since Sawaya et al. ${ }^{(11)}$ reported that $9 \%$ of households in Brazil had overweight and undernourished members living together, in total, thirty-five published studies were eligible for inclusion in this literature review. Most were published in 2010 or later, indicating that this topic has attracted greater academic interest in recent years.

The national prevalence of households with a double burden in this review varied from 0.0 to $26 \cdot 8 \%$ and was $<10 \%$ in many countries. This wide range reflects differences in the combinations of undernourished and overweight persons examined, age ranges, nutritional indicators and cut-off points used, in addition to the involvement of different countries, years and data sources. Some studies focused only on mother-child pairs, whereas others assessed all household members. In addition, age classifications varied markedly among the studies; for example, one study included 12-year-old individuals among adults, whereas another classified 19-year-old individuals as children. Regarding indicators, some studies used HAZ as an indicator of undernutrition, whereas others used WHZ. Because HAZ reflects chronic malnutrition better, it is preferable to WAZ and WHZ for children in studies of the double burden of malnutrition within households. Even among studies in which the same $z$-score was applied, several references were used. Until the release of the international WHO references, the references by the US National Center for Health Statistics (NCHS)/WHO were recommended for the assessment of nutritional status and have been used in studies on the double burden within households. 
However, the NCHS/WHO references were based only on data from the US and did not adequately represent growth in early childhood $^{(46)}$. The difference between the growth curves of the latest WHO references and the NCHS/WHO reference could be substantial especially for weight-for-age and weight-for-height: for example, the $-2 \mathrm{sD}$ of weight-for-age for girls aged 12 months is $7.0 \mathrm{~kg}$ in the latest WHO reference and $7.4 \mathrm{~kg}$ in the NCHS/WHO reference. As the use of different references may result in an individual's nutritional status being classified differently, the results should be interpreted with caution, particularly when the subject is mismatched to the reference population. Because of these differences, the reported figures are not easily compared among the studies, although 367 sets of prevalence values were extracted from the thirty-five studies. On the basis of the age range of the children, the combination of undernourished and overweight persons and nutrition indicators and cut-off points, the largest group that was comparable included only eleven studies (i.e. children $<2$ years old with a HAZ score below -2 and mothers with a BMI $>25.0 \mathrm{~kg} / \mathrm{m}^{2}$ ), excluding two studies that focused on urban or rural areas in the country concerned.

It should be noted that heterogeneity was also found in the sample size and the sampling method, because these factors inevitably affect the strength of evidence. Specifically, studies with a small number of samples and without a clear description of the sampling method should be recognised as showing only weak evidence. Another factor that should be considered is generalisability. Results from studies that analysed the data of a specific population or area should be interpreted carefully. For the above reasons, the results reported in the reviewed studies cannot be considered of equal value.

Nevertheless, trends can be explored, although this is reliant on a small number of studies that calculated prevalence figures for many countries using secondary data. Asian countries and low-income countries tended to have a lower prevalence of stunted child and overweight mother pairs. In addition, among the forty-one countries that were assessed in a manner that allowed comparison, an increase in the prevalence of the double burden of malnutrition was observed in twenty countries whereas a decrease was observed in nine countries. Considering that middle-income countries tended to show a higher prevalence than low-income countries, and that the national income of many low-income countries has increased recently, it is expected that the prevalence of double burden will increase in low-income countries and, as a consequence, in the world. However, to examine the trend more closely, longitudinal studies are needed, which could also facilitate making causal inferences. The distribution of the subject countries and areas suggests another important gap in research. African countries were studied more frequently than Asian countries, although a large part of the world's obese population is in Asia. In addition, whereas many studies assessed low- and middleincome countries, high-income countries have been scarcely studied, although the prevalence is not expected to be high because of the low prevalence of undernutrition.

Studies that conducted original surveys and those that focused on specific countries or areas provided information about factors predictive of the double burden of malnutrition within households. It seems that households with a double burden have certain characteristics in common, although methods and definitions differed by study. An example is urban residence in the country, which was confirmed by a recently published article ${ }^{(47)}$ as well. Others include higher income and a higher level of education of household heads. However, urban residence, higher income and education are unlikely to lead directly to undernutrition or overweight. Rather, a poor nutritional intake and/or imbalance between energy intake and expenditure result in undernutrition and overweight, and these are closely associated with dietary intake and physical activity. Therefore, the linkage between urban residence and the double burden within households may involve inactivity and an obesogenic diet. In addition, the link between education and the double burden may involve knowledge of health and nutrition.

Several studies suggested possible pathways between urban residence, income and education, and dietary intake and physical activity; however, most were speculative, based on earlier studies, and did not use their own findings as evidence. This is likely because they used secondary data and had little information on dietary practices or physical activity. Furthermore, the quality of information on dietary or physical activity in studies in which it was available was insufficient to make a detailed assessment. For example, estimation of the absolute value of nutritional intake using FFQ is less accurate than other methods (e.g. dietary record and dietary recall) ${ }^{(48,49)}$. Future studies should examine the effects on individual diet and physical activity of factors reported to be associated with the double burden within households, using in-depth investigative methods and longitudinal study designs.

Other hypotheses regarding this phenomenon have been proposed. Dieffenbach \& Stein ${ }^{(23)}$ indicated that it is not a distinct phenomenon but a statistical artifact, which is a result only of multiplication dependent on the prevalence of overweight and undernutrition. However, considering that the nutritional statuses of household members are expected to be correlated $^{(17)}$, the prevalence of double-burden households should be smaller than the result of multiplication. Another potential cause is the Barker hypothesis ${ }^{(50)}$. It suggests that nutritional deprivation during fetal growth results in an increased risk for chronic conditions in adulthood, and the relationship has been demonstrated. A longitudinal study would enable assessment of this possibility as a cause of the double burden within households.

This is the first systematic review on this subject. However, several limitations should be taken into consideration. There was a marked heterogeneity in the sample size, sampling methods and analytical methods, which prevented performance of a meta-analysis. Another limitation is the possibility of the incomplete retrieval of studies. Because the double (or dual) burden of malnutrition is a relatively new term, studies that did not use the term may not have been identified. To minimise this possibility, a post hoc search was conducted, and the cited articles were screened. Likewise, literatures published in a language other than English were not included even if they provided a summary written in English, as the details of the study cannot be assessed in the review process. 
In summary, the national prevalence of households with a double burden was generally $<10 \%$ and was even lower in Asian countries and low-income countries. However, an increasing trend was expected in low-income countries, suggesting that the prevalence will increase further. Future studies should perform longitudinal observations using comparable indicators and cut-off points, involve Asian countries, and investigate individual dietary intake and physical activity. As the prevalence of households with a double burden of malnutrition has increased, and is expected to increase further in the future, the importance of studying the double burden of malnutrition within households will increase concomitantly.

\section{Acknowledgements}

No financial support was received for this study.

S. K. designed and carried out the literature review, and wrote the first draft. S. K. and M. U. revised the draft.

None of the authors has any conflicts of interest to declare.

\section{Supplementary material}

For supplementary material/s referred to in this article, please visit https://doi.org/10.1017/S0007114517000812

\section{References}

1. Beaglehole R \& Yach D (2003) Globalisation and the prevention and control of non-communicable disease: the neglected chronic diseases of adults. Lancet 362, 903-908.

2. Mendis S, Armstrong T, Bettcher D, et al. (2015) Global Status Report on Noncommunicable Diseases 2014. Geneva: WHO.

3. Doak CM, Adair LS, Bentley M, et al. (2005) The dual burden household and the nutrition transition paradox. Int $J$ Obes (Lond) 29, 129-136.

4. Popkin BM (1993) Nutritional patterns and transitions. Popul Dev Rev 19, 138-157.

5. Popkin BM (1998) The nutrition transition and its health implications in lower-income countries. Public Health Nutr $\mathbf{1}$, 5-21.

6. Shrimpton R \& Rokx C (2013) Double burden of malnutrition. http:/tulane.edu/publichealth/internut/upload/08-04.pdf (accessed December 2015)

7. Haddad L, Cameron L \& Barnett I (2014) The double burden of malnutrition in SE Asia and the Pacific: priorities, policies and politics. Health Policy Plan (Epublication ahead of print version 15 October 2014).

8. Ruel MT \& Alderman H, \& Maternal and Child Nutrition Study Group (2013) Nutrition-sensitive interventions and programmes: how can they help to accelerate progress in improving maternal and child nutrition? Lancet 382, 536-551.

9. Prentice AM (2006) The emerging epidemic of obesity in developing countries. Int J Epidemiol 35, 93-99.

10. Delisle HF (2008) Poverty: the double burden of malnutrition in mothers and the intergenerational impact. Ann $N$ Y Acad Sci 1136, 172-184.

11. Sawaya AL, Dallal G, Solymos G, et al. (1995) Obesity and malnutrition in a Shantytown population in the city of São Paulo, Brazil. Obes Res 3, 107s-115s.

12. Doak CM, Adair LS, Monteiro C, et al. (2000) Overweight and underweight coexist within households in Brazil, China and Russia. J Nutr 130, 2965-2971.
13. Doak CM, Adair L, Bentley M, et al. (2002) The underweight/ overweight household: an exploration of household sociodemographic and dietary factors in China. Public Health Nutr 5, 215-221.

14. Angeles-Agdeppa I, Lana RD \& Barba CVC (2003) A case study on dual forms of malnutrition among selected households in District 1, Tondo, Manila. Asia Pac J Clin Nutr 12, 438-446.

15. Khor GL \& Sharif ZM (2003) Dual forms of malnutrition in the same households in Malaysia - a case study among Malay rural households. Asia Pac J Clin Nutr 12, 427-437.

16. Garrett JL \& Ruel MT (2005) The coexistence of child undernutrition and maternal overweight: prevalence, hypotheses, and programme and policy implications. Matern Child Nutr $\mathbf{1}$, 185-196.

17. Garrett JL \& Ruel MT (2005) Stunted child-overweight mother pairs: prevalence and association with economic development and urbanization. Food Nutr Bull 26, 209-221.

18. Raphael D, Delisle H \& Vilgrain C (2005) Households with undernourished children and overweight mothers: is this a concern for Haiti? Ecol Food Nutr 44, 147-165.

19. Barquera S, Peterson KE, Must A, et al. (2007) Coexistence of maternal central adiposity and child stunting in Mexico. Int J Obes (Lond) 31, 601-607.

20. Jehn M \& Brewis A (2009) Paradoxical malnutrition in motherchild pairs: untangling the phenomenon of over- and undernutrition in underdeveloped economies. Econ Hum Biol 7, $28-35$.

21. Saibul N, Shariff ZM, Lin KG, et al. (2009) Food variety score is associated with dual burden of malnutrition in Orang Asli (Malaysian indigenous peoples) households: implications for health promotion. Asia Pac J Clin Nutr 18, 412-422.

22. Lee J, Houser RF, Must A, et al. (2010) Disentangling nutritional factors and household characteristics related to child stunting and maternal overweight in Guatemala. Econ Hum Biol 8, 188-196.

23. Dieffenbach S \& Stein AD (2012) Stunted child/overweight mother pairs represent a statistical artifact, not a distinct entity. J Nutr 142, 771-773.

24. Dop MC, Pereira C, Mistura L, et al. (2012) Using Household Consumption and Expenditures Survey (HCES) data to assess dietary intake in relation to the nutrition transition: a case study from Cape Verde. Food Nutr Bull 33, S221-S227.

25. Grijalva-Eternod CS, Wells JC, Cortina-Borja M, et al. (2012) The double burden of obesity and malnutrition in a protracted emergency setting: a cross-sectional study of Western Sahara refugees. PLos Med $\mathbf{9}$, e1001320.

26. Lee J, Houser RF, Must A, et al. (2012) Socioeconomic disparities and the familial coexistence of child stunting and maternal overweight in Guatemala. Econ Hum Biol 10, 232-241.

27. Oddo VM, Rah JH, Semba RD, et al. (2012) Predictors of maternal and child double burden of malnutrition in rural Indonesia and Bangladesh. Am J Clin Nutr 95, 951-958.

28. Varela-Silva MI, Dickinson F, Wilson H, et al. (2012) The nutritional dual-burden in developing countries - how is it assessed and what are the health implications? Coll Antropol 36, 39-45.

29. Ihab AN, Rohana AJ, Manan WM, et al. (2013) The coexistence of dual form of malnutrition in a sample of rural Malaysia. Int J Prev Med 4, 690-699.

30. Ponce MC, Incani RN, Pinelli E, et al. (2013) Are intestinal parasites fuelling the rise in dual burden households in Venezuela? Trans R Soc Trop Med Hyg 107, 119-123.

31. Roemling C \& Qaim M (2013) Dual burden households and intra-household nutritional inequality in Indonesia. Econ Hum Biol 11, 563-573. 
32. Bassete MN, Romaguera D, Gimenez MA, et al. (2014) Prevalence and determinants of the dual burden of malnutrition at the household level in Puna and Quebrada of Humahuaca, Jujuy, Argentina. Nutr Hosp 29, 322-330.

33. Conde WL \& Monteiro CA (2014) Nutrition transition and double burden of undernutrition and excess of weight in Brazil. Am J Clin Nutr 100, 1617S-1622S.

34. Freire WB, Silva-Jaramillo KM, Ramirez-Luzuriaga MJ, et al. (2014) The double burden of undernutrition and excess body weight in Ecuador. Am J Clin Nutr 100, 1636S-1643S.

35. Kroker-Lobos MF, Pedroza-Tobias A, Pedraza LS, et al. (2014) The double burden of undernutrition and excess body weight in Mexico. Am J Clin Nutr 100, 1652S-1658S.

36. Leroy JL, Habicht JP, Gonzalez de Cossio T, et al. (2014) Maternal education mitigates the negative effects of higher income on the double burden of child stunting and maternal overweight in rural Mexico. J Nutr 144, 765-770.

37. Ramirez-Zea M, Kroker-Lobos MF, Close-Fernandez R, et al. (2014) The double burden of malnutrition in indigenous and nonindigenous Guatemalan populations. Am J Clin Nutr $\mathbf{1 0 0}$, 1644S-1651S

38. Sarmiento OL, Parra DC, Gonzalez SA, et al. (2014) The dual burden of malnutrition in Colombia. Am J Clin Nutr 100, 1628S-1635S

39. Severi C \& Moratorio X (2014) Double burden of undernutrition and obesity in Uruguay. Am J Clin Nutr 100, 1659S-1662S.

40. Vaezghasemi M, Ohman A, Eriksson M, et al. (2014) The effect of gender and social capital on the dual burden of malnutrition: a multilevel study in Indonesia. PLOS ONE 9, e103849.

41. Wojcicki JM (2014) The double burden household in SubSaharan Africa: maternal overweight and obesity and childhood undernutrition from the year 2000: results from World Health Organization data (WHO) and Demographic Health Surveys (DHS). BMC Public Health 14, 1124.
42. Aitsi-Selmi A (2015) Households with a stunted child and obese mother: trends and child feeding practices in a middle-income country, 1992-2008. Matern Child Health J 19, 1284-1291.

43. Kimani-Murage EW, Muthuri SK, Oti SO, et al. (2015) Evidence of a double burden of malnutrition in urban poor settings in Nairobi, Kenya. PLOS ONE 10, e0129943.

44. Parra DC, Iannotti L, Gomez LF, et al. (2015) The nutrition transition in Colombia over a decade: a novel household classification system of anthropometric measures. Arch Public Health 73, 12

45. Rae AN (1999) Food consumption patterns and nutrition in urban Java households: the discriminatory power of some socioeconomic variables. Aust J Agric Resour Econ $\mathbf{4 3}$, 359-383.

46. de Onis M (2006) WHO child Growth Standards: Length/ Height-for-Age, Weight-for-Age, Weight-for-Length, Weightfor-Height and Body Mass Index-for-Age. Geneva: WHO.

47. Jones AD, Acharya Y \& Galway LP. (2016) Urbanicity gradients are associated with the household- and individual-level double burden of malnutrition in Sub-Saharan Africa. $J$ Nutr 146, 1257-1267.

48. Schatzkin A, Kipnis V, Carroll RJ, et al. (2003) A comparison of a food frequency questionnaire with a 24-hour recall for use in an epidemiological cohort study: results from the biomarkerbased Observing Protein and Energy Nutrition (OPEN) study. Int J Epidemiol 32, 1054-1062.

49. Bingham SA, Gill C, Welch A, et al. (1994) Comparison of dietary assessment methods in nutritional epidemiology: weighed records v. $24 \mathrm{~h}$ recalls, food-frequency questionnaires and estimated-diet records. $\mathrm{Br} J \mathrm{Nutr} \mathbf{7 2}$, 619-643.

50. Barker DJ. (1997) Maternal nutrition, fetal nutrition, and disease in later life. Nutrition 13, 807-813. 